Jurnal Media Analis Kesehatan, Vol. 8, No.2, November 2017

http://journal.poltekkes-mks.ac.id/ojs2/index.php/mediaanalis

e-ISSN : 2621-9557

p-ISSN : 2087-1333

\title{
ANALISIS NATRIUM BENZOAT PADA MIE INSTANT YANG DIPERDAGANGKAN DI KOTA MAKASSAR
}

\author{
Artati \\ Jurusan Analis Kesehatan Poltekkes Kemenkes Makassar \\ Koresponden: tatigiland@ rocketmail.com
}

\begin{abstract}
ABSTRAK
Penelitian ini dilatarbelakangi oleh banyak jenis pengawet yang digunakan untuk mengawetkan bahan pangan salah satu bahan pengawet yang sering dipakai pada mie adalah natrium benzoat. Penambahan bahan pengawet natrium benzoate pada bahan pangan tidak dilarang pemerintah. Namun, produsen hendaknya tidak menambahkan jenis bahan pengawet ini sesuka hati, karena bahan pengawet ini akan merugikan kesehatan jika bahan pengawet ini dipakai secara berlebihan. Tujuan penelitian ini untuk menentukan kadar pengawet natrium benzoat dalam mie instan yang di perdagangkan di kota Makassar. Penelitian ini telah dilakukan pada tanggal 12 - 13 Juni 2017 di Balai Besar Laboratorium Kesehatan Makassar. Jenis penelitian ini bersifat deskriptif dimana sampel yang digunakan sebanyak 5 sampel dengan teknik pengambilan sampel secara purposive sampling. Dari hasil penelitian menunjukkan hasil analisis natrium benzoat pada mie instant sebanyak 5 sampel yang diperdagangkan di Kota Makassar. Kadar natrium benzoat yang tertinggi pada mie instant terdapat pada sampel no 5 yaitu $9.1033 \mathrm{mg} / \mathrm{kg}$ dan kadar natrium benzoate pada mie instant yang terendah pada mie instant terdapat pada sampel no 2 yaitu 0.9194 $\mathrm{mg} / \mathrm{kg}$. Disarankan kepada masyarakat untuk berhati-hati dalam memilih makanan dan tidak mengonsumsi mie instan secara berlebihan terutama mie instan yang mengandung kadar Natrium Benzoat tinggi.
\end{abstract}

Kata kunci : Kadar Natrium Benzoat, Mie Instan

\section{PENDAHULUAN}

Kesehatan adalah hal terpenting dalam kehidupan manusia, kesadaran pentingnya menjaga kesehatan tersebut biasanya timbul ketika kita mengalami penyakit tertentu. Di saat itulah, kita akan mengatakan enaknya hidup sehat. Dalam kehidupan seharihari, sebenarnya yang termudah dan tersulit untuk menjaga kesehatan adalah dengan memperhatikan asupan makanan dan minuman.
Banyak masyarakat yang tertarik pada bahan pangan tertentu seperti bahan pangan dalam kaleng,botol dan dalam bentuk kemasan lainnya dari hasil produksi industri bahan pangan, sebagai contoh bahan pangan keluaran pabrik pada umumnya menggunakan bahan tambahan pangan termasuk di dalamnya adalah bahan pengawet yang secara sengaja ditambahkan agar bahan pangan yang dihasilkan memiliki masa simpan lebih lama dan 
Jurnal Media Analis Kesehatan, Vol. 8, No.2, November 2017

http://journal.poltekkes-mks.ac.id/ojs2/index.php/mediaanalis

e-ISSN : 2621-9557

p-ISSN : 2087-1333

dapat dipertahankan kualitasnya (Cahyadi, 2008).

Banyak jenis pengawet yang digunakan untuk mengawetkan bahan pangan salah satu bahan pengawet yang sering dipakai pada mie adalah natrium benzoat. Benzoat juga sering digunakan untuk mengawetkan sari buah, minuman ringan, saus sambal, selai, jeli manisan dan lain-lain. (Cahyadi, 2008).

Penambahan bahan pengawet natrium benzoate pada bahan pangan tidak dilarang pemerintah. Namun, produsen hendaknya tidak menambahkan jenis bahan pengawet ini sesuka hati, karena bahan pengawet ini akan merugikan kesehatan jika bahan pengawet ini dipakai secara berlebihan. Pada penderita asma dan urticarial sangat sensitive terhadap asam benzoate dan jika di konsumsi dalam jumlah besar akan mengiritasi lambung (Cahyadi, 2008).

Oleh karena itu perlu dilakukan penelitian untuk menentukan kadar bahan pengawet natrium benzoate pada mie instan apakah sesuai dengan standar permenkes No. 722 tentang bahan tambahan pangan. Tujuan Penelitian adalah untuk menentukan kadar pengawet natrium benzoat dalam mie instan yang di perdagangkan di kota Makassar

\section{METODE}

Jenis, Lokasi dan Waktu Penelitian Jenis penelitian ini adalah deskriptif tentang analisis natrium benzoat pada mie instant. Penelitian ini telah dilaksanakan Di Balai Besar Laboraturium Kesehatan Makassar pada tanggal 12-13 juni 2017.

\section{Populasi dan Sampel}

Populasi penelitian adalah semua mie instan yang di perdangangkan di kota Makassar. Sampel penelitian ini adalah mie instan yang di perdangangkan di kota Makassar sebanyak 5 sampel. Alat

Alat yang digunakan yaitu: Labu ukur, kertas saring, pipet tetes, penangas air, corong, batang pengaduk, corong pemisah, Erlenmeyer, pipet volume, kertas lakmus, buret, dan stand buret. Bahan yang digunakan yaitu: $\mathrm{NaCl}$ jenuh, $\mathrm{NaOH} 10 \%, \mathrm{HCl}(1: 3), \mathrm{NH} 4 \mathrm{OH}$ $10 \%, \mathrm{FeCl} 35 \%$, Klorofrom, etanol netral, Indikator fenolftalein, $\mathrm{NaOH}$ $0,05 \mathrm{~N}$ dan mie instan.

\section{Prosedur Penelitian}

Persiapan sampel

Sampel dihaluskan dan dihomogenkan, Kemudian ditimbang 10 gram sampel, di homogenkan dengan aquadest selama 1 jam. Lalu disaring dan tambahkan $0,4 \mathrm{ml} \mathrm{HCl}$ 1:1,di ekstraksi dengan petroleum benzene. Volume ekstrak ditepatkan dengan petroleum benzene dalam labu ukur.

Prosedur Kerja

Sampel di timbang terlebih dahulu,setelah dihaluskan dan homogenkan dengan aquadest selama 1 jam. Setelah di saring dengan kasa, lalu di tambahkan $\mathrm{HCl} 0,4 \mathrm{ml}$, dan masukkan ke dalam corong pisah kemudian di ekstraksi. Di ekstraksi dengan natrium benzoate, hasil ekstraksi di masukkan ke dalam labu ukur $50 \mathrm{ml}$. Kemudian di diamkan selama beberapa hari sampai menguap, Setelah menguap di tambahkan $5 \mathrm{ml}$ natrium benzoate ke 
Jurnal Media Analis Kesehatan, Vol. 8, No.2, November 2017

http://journal.poltekkes-mks.ac.id/ojs2/index.php/mediaanalis

e-ISSN : 2621-9557

p-ISSN : 2087-1333

dalam masing-masing labu ukur. Lalu dihomogenkan dan diperiksa di spektrofotometer UV VIS.

Analisa data yang digunakan pada penelitian ini adalah dalam bentuk tabel yang disertai narasi yang diolah secara deskriptif.

\section{HASIL}

Berdasarkan hasil analisis Natrium Benzoat Pada Mie Instant Yang Diperdagangkan Di Kota Makassar dengan menggunakan mie instan sebanyak 5 sampel dari berbagai merek yang berbeda, dilakukan secara random sampling menggunakan metode ekstraksi

Tabel 1.

Hasil Natrium Benzoat Pada MieInstant Yang Diperdagangkan Di Kota Makassar

\begin{tabular}{ccc}
\hline Kode Sampel & Satuan & Natrium Benzoat \\
\hline 1 & $\mathrm{mg} / \mathrm{kg}$ & 3.4310 \\
2 & $\mathrm{mg} / \mathrm{kg}$ & 0.9194 \\
3 & $\mathrm{mg} / \mathrm{kg}$ & 2.8272 \\
4 & $\mathrm{mg} / \mathrm{kg}$ & 8.3446 \\
5 & $\mathrm{mg} / \mathrm{kg}$ & 9.1033 \\
\hline
\end{tabular}

Dari tabel 1. menunjukkan hasil analisis natrium benzoate pada mie instant sebanyak 5 sampel yang diperdagangkan di Kota Makassar. Kadar natrium benzoate yang tertinggi pada mie instant terdapat padasampel no 5 yaitu $9.1033 \mathrm{mg} / \mathrm{kg}$ dan kadar natrium benzoate pada mie instant yang terendah pada mie instant terdapat pada sampel no 2 yaitu 0.9194 $\mathrm{mg} / \mathrm{kg}$

\section{PEMBAHASAN}

Dalam analsis kadar natrium benzoate digunakan sampel mie instant sebanyak lima jenis dengan merek yang berbeda yang diperdagangkan dikota makassar. Hasil penelitian ini didapatkan nilai tertinggi pada sampel no 5 yaitu $9.1033 \mathrm{mg} / \mathrm{kg}$ dan kadar natrium benzoate pada mie instant yang terendah pada mie instant terdapat pada sampel no 2 yaitu $0.9194 \mathrm{mg} / \mathrm{kg}$.
Dalam pengujian ini, prosedur yang digunakan adalah ekstraksi. Sebelum dilakukan ekstraksi sampel terlebih dahulu di haluskan dan disaring kemudian diasamkan dengan penambahan $\mathrm{HCl}$ 1:1 yang berfungsi untuk mempercepat pemisahan larutan pada proses ekstraksi. Setelah itu diekstrak dengan larutan petroleum benzoate. Hasil ekstraksi dibaca dengan menggunakan spektrofotometer UV VIS panjang gelombang $225 \mathrm{~nm}$.

Dari hasil penelitian yang telah dilakukan diperoleh kadar natrium benzoate pada sampel 4 dan 5 dengan kadar natrium benzoate yang melebihi ambang batas yang telah ditentukan oleh BPOM $0-5 \mathrm{mg} / \mathrm{kg}$.

\section{KESIMPULAN}

Dari hasil analisis Natrium Benzoat Pada Mie Instant Yang Diperdagangkan Di Kota Makassar, maka dapat disimpulkan bahwa kelima 
Jurnal Media Analis Kesehatan, Vol. 8, No.2, November 2017

http://journal.poltekkes-mks.ac.id/ojs2/index.php/mediaanalis

e-ISSN : 2621-9557

p-ISSN : 2087-1333

sampel yang diperiksa hanya sampel 4 dan 5 yang melebihi ambang batas. Kadar natrium benzoat pada sampel 4 yaitu $8.3446 \mathrm{mg} / \mathrm{kg}$ dan sampel 5 yaitu $9.1033 \mathrm{mg} / \mathrm{kg}$. kandungan natrium benzoat yang terdapat dalam sampel tersebut melebihi ambang batas yang ditentukan oleh BPOM yaitu $0-5$ $\mathrm{mg} / \mathrm{kg}$.

\section{SARAN}

Dalam hasil penelitian ini, peneliti dapat menyarankan hal-hal sebagai berikut :

1. Disarankan kepada masyarakat untuk berhati-hati dalam memilih makanan dan tidak mengonsumsi mie instan secara berlebihan terutama mie instan yang mengandung kadar Natrium Benzoat diatas nilai ambang batas yg telah ditetapkan..

2. Disarankan untuk peneliti selanjutnya agar perlu dilakukan penentuan kadar Natrium Benzoat menggunakan bumbu pada mie instan.

\section{DAFTAR PUSTAKA}

Cahyadi Wisnu, 2008. Analisis dan Aspek Kesehatan Bahan Tambahan Pangan. Bumi Aksara. Jakarta.

Dachriyanus, 2004. Analisis Struktur Senyawa Organik Secara Spektroskopi. Padang: Andalas University Press.

Harjadi W, 2008. Ilmu Kimia Analitik Dasar. Gramedia. Makassar. Handayana A, 2004. Kamus Kimia. Balai Pustaka. Jakarta.

Kokasih et al. 2004. Asas Pengembangan Prosedur
Analisis. Edisi Pertama.

Surabaya: Airlangga University Press.

Lemini. 2004. Toksikologi dan Kesehatan Industri. Gajah mada University Press. Yogyakarta. Pudjaatmaka A, 2004. Kamus Kimia. Balai Pustaka. Jakarta.

Rohman A, 2007. Analisis Makanan. Gajah Mada University Press. Yogyakarta.

S Syukri, 2004. Kimia Dasar 2. Institusi Teknik Bandung. Bandung. Petrokimia Fakultas Teknik Universitas Indonesia. Jakarta.

Winarno F, 2004. Kimia Pangan dan Gizi. PT. Gramedia Pustaka Utama. Jakarta.

Yuliarti Nurheti, 2007. Awas! Bahaya Di Balik Lezatnya Makanan. Andi. Yogyakarta. 